\title{
PENGARUH STRES KERJA TERHADAP KINERJA KARYAWAN DIMEDIASI OLEH KEPUASAN KERJA KARYAWAN PT. DESTINATION ASIA BALI
}

\author{
Ade Agus Diama Purwa Diputra ${ }^{1}$ \\ Ida Bagus Ketut Surya ${ }^{2}$ \\ ${ }^{1,2}$ Fakultas Ekonomi dan Bisnis Universitas Udayana (Unud), Bali, Indonesia \\ e-mail: adeagusd@yahoo.co.id
}

\begin{abstract}
ABSTRAK
Tujuan penelitian ini untuk mengetahui dan menganalisis pengaruh langsung stress kerja dan kepuasan kerja terhadap kinerja karyawan, untuk mengetahui dan menganalisis pengaruh langsung stres kerja terhadap kepuasan kerja, serta untuk mengetahui dan menganalisis pengaruh kepuasan kerja dalam memediasi pengaruh stress kerja terhadap kinerja karyawan pada PT. Destination Asia Bali. Hasil penelitian menunjukkan bahwa stres kerja berpengaruh negatif dan signfikan terhadap kepuasan kerja dan kinerja karyawan, kepuasan kerja berpengaruh positif dan signifikan terhadap kinerja karyawan, kepuasan kerja secara positif dan signifikan memediasi pengaruh stres kerja terhadap kinerja karyawan. Populasi dalam penelitian ini adalah seluruh karyawan tetap pada PT. Destination Asia Bali. Karyawan tetap dipilih menjadi populasi penelitian karena diasumsikan bahwa karyawan tersebut memiliki informasi lebih banyak mengenai kondisi perusahaan. Pengambilan sampel dalam penelitian ini menggunakan teknik sampel jenuh atau sensus, sehingga jumlah sampel penelitian sebanyak 56 orang karyawan. Data dikumpulkan menggunakan kuesioner kemudian dianalisis menggunakan teknik analisis jalur (Path Analysis).
\end{abstract}

Kata kunci: stres kerja, kepuasan kerja, kinerja karyawan

\begin{abstract}
The purpose of this study was to determine and analyze the direct influence of work stress and job satisfaction on employee performance, to determine and analyze the direct effect of work stress on job satisfaction, as well as to know and analyze the effect of job satisfaction in mediating the effect of work stress on employee performance at PT. Destination Asia Bali. The results showed that work stress had a negative and significant effect on job satisfaction and employee performance, job satisfaction had a positive and significant effect on employee performance, job satisfaction positively and significantly mediated the effect of work stress on employee performance. The population in this study were all permanent employees at PT. Destination Asia Bali. Employees remain selected as research population because it is assumed that the employee has more information about the condition of the company. Sampling in this study uses saturated sample or census techniques, so the number of research samples is 56 employees. Data were collected using a questionnaire then analyzed using Path Analysis techniques.
\end{abstract}

Keywords: job stress, job satisfaction, employee performance 


\section{PENDAHULUAN}

Bali sebagai salah satu objek wisata yang terkenal di dunia memperoleh peringkat pertama di dunia dalam Travellers Choice 2018. Situs ulasan dan panduan wisata asal Amerika Serikat, TripAdvisor, membagikan daftar 25 negara yang masuk dalam "Travellers Choice 2018" pada 7 Maret 2018. Hasilnya, Indonesia berada pada peringkat pertama dengan Bali sebagai destinasi wisata terbaik di dunia. Aspek yang dinilai dalam kategori ini termasuk keindahan dan kondisi wisata alam, kualitas akomodasi, seperti hotel, resort, bungalow, dan lainlain. Ulasan wisatawan soal kenyamanan selama berlibur juga menjadi faktor penilaian. Bali sukses mengalahkan negara yang masuk lima besar lainnya seperti London, Paris, Roma, dan New York (Cahya, 2018). Bali selama ini menjadi daya tarik terbesar kunjungan wisatawan asing ke Indonesia. Hal tersebut dibuktikan dengan tingginya minat wisatawan yang berkunjung ke Bali.

Seiring dengan laju wisatawan yang berkunjung ke Bali dan sektor pariwisata yang semakin berkembang maka terciptalah travel agent atau Biro Perjalanan Wisata yang memiliki fungsi untuk memberikan kemudahan dalam mengakses informasi tentang pariwisata di Bali. Travel agent atau Biro Perjalanan Wisata juga memberikan konstribusi yang besar dalam peningkatan jumlah wisatawan ini (Subawa, 2017). Salah satu Travel agent yang turut serta dalam hal ini adalah PT. Destination Asia Bali. Sebagai salah satu penyedia layanan jasa wisata di Bali, PT. Destination Asia Bali harus bisa memberikan kinerja yang maksimal, agar dapat bersaing dan unggul dibandingkan penyedia layanan jasa 
Ade Agus Diama Purwa Diputra, Pengaruh Stres Kerja Terhadap Kinerja Karyawan...]

wisata di Bali lainnya. Organisasi/perusahaan harus mampu menjaga kinerja karyawan agar tetap stabil bahkan meningkat.

Kinerja merefleksikan seberapa baik karyawan memenuhi persyaratan sebuah pekerjaan. Faktor-faktor yang mempengaruhi kinerja karyawan adalah kepuasan kerja, komitmen organisasional, motivasi, leader member exchange atau kepemimpinan, pendidikan, disiplin kerja, ketrampilan, sikap etika kerja, gizi dan kesehatan, tingkat gaji, lingkungan kerja dan iklim kerja, teknologi, sarana produksi, jaminan sosial, manajemen, dan kesempatan promosi jabatan (Narmodo, 2009). Salah satu faktor yang mempengaruhi kinerja karyawan adalah kepuasan kerja karyawan.

Berdasarkan hasil wawancara dengan manajer PT. Destination Asia Bali, terdapat masalah mengenai keluhan-keluhan yang dialami oleh karyawan tentang pekerjaannya, yang menunjukkan bahwa karyawan memiliki kepuasan kerja yang rendah. Indikasi masalah rendahnya kepuasan kerja karyawan di PT. Destination Asia Bali menyebabkan kinerja karyawan rendah. Indikator rendahnya kinerja karyawan PT. Destination Asia Bali disajikan pada Tabel 1 sebagai berikut.

Tabel 1.

Indikator Rendahnya Kinerja Karyawan PT. Destination Asia Bali Indikator Kinerja

\begin{tabular}{cc}
\hline Indikator Kinerja & Faktor Kinerja Rendah \\
\hline Kualitas Kerja & Masih terdapat karyawan yang bermalas-malasan \\
Kehadiran dan Ketepatan Waktu & dalamengerjakan pekerjaannya \\
Inisiatif & $\begin{array}{c}\text { Masih ada karyawan yang hadirnya tidak tepat waktu } \\
\text { Kurangnya tanggungjawab dari karyawan dalam }\end{array}$ \\
Komunikasi & menyelesaikan tugas-tugasnya. \\
& Masih adanya komunikasi yang buruk antara \\
karyawan satu dengan karyawan lainya
\end{tabular}

Sumber :PT. Destination Asia Bali, 2018

Karyawan yang kurang mendapatkan kepuasan kerja cenderung lebih sering absen (Handoko, 2008:197). Berdasarkan hasil observasi dan wawancara dengan 
manajer PT. Destination Asia Bali menunjukkan masih banyak karyawan yang hadir tidak tepat waktu saat bekerja. Kondisi tersebut di dukung dengan data yang diperoleh peneliti mengenai banyaknya kejadian datang lebih dari waktu kerja yang sudah ditentukan dan pulang sebelum waktu kerja berakhir, seperti yang di rangkum dalam Tabel 2 sebagai berikut :

Tabel 2.

Banyaknya kejadian datang lebih dari pukul 08.00 WITA dan pulang kurang dari pukul 17.00 WITA

\begin{tabular}{lcc}
\hline \multirow{2}{*}{ Bulan } & \multicolumn{2}{c}{ Banyak Kejadian } \\
\cline { 2 - 3 } & $\begin{array}{c}\text { Datang } \\
\text { 08.00 WITA }\end{array}$ & $\begin{array}{c}\text { Pulang } \\
\text { 17.00 WITA }\end{array}$ \\
\hline Januari & 8 & 9 \\
Februari & 6 & 8 \\
Maret & 6 & 4 \\
April & 7 & 3 \\
Mei & 4 & 4 \\
Juni & 2 & 5 \\
Juli & 3 & 4 \\
Agustus & 3 & 3 \\
September & 4 & 5 \\
Oktober & 4 & 2 \\
\hline Sumbi: PT. Deting
\end{tabular}

Sumber: PT. Destination Asia Bali, 2018

Pada Tabel 2 dapat dicermati bahwa karyawan yang datang lebih dari pukul 08.00 WITA dan pulang kurang dari pukul 17.00 WITA dapat dikatakan relatif tinggi, oleh karena itu kejadian ini harus menjadi perhatian serius bagi pihak manajemen karena jika kejadian ini dibiarkan secara terus menerus maka tidak menutup kemungkinan akan terjadi peningkatan kejadian serupa yang nantinya akan berdampak pada kinerja perusahaan secara keseluruhan. Pihak manajemen harus mempertimbangkan kebijakan yang tepat guna menindaklanjuti kejadian ini, seperti pemberian teguran secara langsung, pemberian peringatan, dan pemberian sanksi dapat menjadi pilihan untuk dipertimbangkan. Indikasi rendahnya tingkat 
Ade Agus Diama Purwa Diputra, Pengaruh Stres Kerja Terhadap Kinerja Karyawan...]

kepuasan kerja karyawan PT. Destination Asia Bali dapat dilihat dari tingkat absensi karyawan yang dapat dilihat pada Tabel 3.

Tabel 3.

Tingkat Absensi Karyawan PT. Destination Asia Bali Tahun 2017

\begin{tabular}{cccccccc}
\hline No & Bulan & $\begin{array}{c}\text { Hari } \\
\text { Kerja }\end{array}$ & $\begin{array}{c}\text { Jumlah } \\
\text { Karyawan } \\
\text { (Orang) }\end{array}$ & $\begin{array}{c}\text { Jumlah Hari } \\
\text { Kerja } \\
\text { Seharusnya }\end{array}$ & $\begin{array}{c}\text { Absensi } \\
\text { (Hari) }\end{array}$ & $\begin{array}{c}\text { Jumlah } \\
\text { Kehadiran } \\
\text { Karyawan } \\
\text { (Hari) }\end{array}$ & $\begin{array}{c}\text { Prosentase } \\
\text { Absensi } \\
\text { Karyawan } \\
(\%)\end{array}$ \\
\hline & & A & C & D = BxC & E & F = D-E & $\begin{array}{c}\text { G }= \\
\text { E/D.100 }\end{array}$ \\
\hline 1 & Januari & 22 & 56 & 1232 & 43 & 1189 & 3.49 \\
2 & Februari & 20 & 55 & 1100 & 45 & 1055 & 4.09 \\
3 & Maret & 20 & 58 & 1160 & 46 & 1114 & 3.96 \\
4 & April & 21 & 57 & 1197 & 48 & 1149 & 4.01 \\
5 & Mei & 22 & 55 & 1210 & 45 & 1165 & 3.72 \\
6 & Juni & 20 & 57 & 1140 & 44 & 1096 & 3.86 \\
7 & Juli & 22 & 54 & 1188 & 43 & 1145 & 3.62 \\
8 & Agustus & 22 & 54 & 1188 & 42 & 1146 & 3.53 \\
9 & September & 20 & 52 & 1040 & 46 & 994 & 4.42 \\
10 & Oktober & 21 & 56 & 1176 & 47 & 1129 & 3.99 \\
11 & November & 22 & 55 & 1210 & 45 & 1165 & 3.72 \\
12 & Desember & 22 & 56 & 1232 & 46 & 1186 & 3.73 \\
\hline
\end{tabular}

Sumber: PT. Destination Asia Bali, 2018

Rata-rata tingkat absensi karyawan PT. Destination Asia Bali bulan Januari sampai dengan Desember pada tahun 2017 yaitu pada presentase 3.84. Flippo (2002:281) menyatakan bahwa apabila absensi 0 sampai 2 persen dinyatakan baik, 3 sampai 10 persen dinyatakan disiplin kerja yang rendah dan diatas 10 persen dinyatakan tidak wajar. Kemangkiran atau tidak masuk kerja (absen) karyawan tanpa alasan merupakan keadaan yang tidak menguntungkan perusahaan. Dengan tingkat absensi diatas 3 persen, ini merupakan salah satu indikasi adanya masalah dalam kepuasan kerja karyawan PT. Destination Asia Bali. 
Kepuasan kerja timbul akibat cara yang ditunjukan para manajer dalam memperhatikan dan meminta pendapat serta keikutsertaan bawhannya, sehingga para pekerja merasa bahwa mereka mmerupakan bagian dari internal organisasi dari organisasinya dan merasa bahwa atasan memperhatikan mereka (Firmansah dan Santy, 2011). Susanty (2012) menekankan kepuasan kerja karyawan harus diciptakan sebaik-baiknya agar modal kerja, dedikasi, kecintaan, dan kedisiplinan karyawan meningkat.Kepuasan kerja merupakan apa yang dirasakan seseorang mengenai pekerjaannya. Seorang merasa puas dengan pekerjaannya jika pekerjaan tersebut sesuai dengan harapan mereka (Chen et al., 2010).

Rendahnya kepuasan kerja karyawan diduga ada hubungannya dengan stres kerja. Hasil penelitian Faqihudin dan Gunistiyo (2010) diketahui stres kerja mempunyai pengaruh signifikan dan negatif terhadap kepuasan kerja karyawan. Stres adalah suatu kondisi dinamis dimana seorang individu diharapkan pada peluang, tuntutan, atau sumber daya yang terkait dengan apa yang diharuskan oleh individu itu dan hasilnya dipandang tidak pasti dan penting, stres sendiri tidak mesti buruk meskipun biasanya dibahas dalam konteks negatif stres juga memiliki nilai positif, dari sudut pandang organisasi manajemen mungkin tidak peduli ketika karyawan mengalami tingkat stres rendah hingga menengah (Robbins, 2008:337). Stres juga merupakan kondisi yang menjadi komponen yang berbeda termasuk tekanan emosional, khawatir, dan hilangnya keterlibatan dalam melaksanakan tugas (Matthews et al., 2002). Penelitian Adawiyah (2015) menyebutkan bahwa meskipun adanya stres kerja tetapi apabila ditunjang dengan kepuasan kerja yang tinggi maka kinerja karyawan akan maksimal dalam bekerja. 
Ade Agus Diama Purwa Diputra, Pengaruh Stres Kerja Terhadap Kinerja Karyawan...]

Sehingga dapat disimpulkan bahwa kepuasan kerja mampu memediasi pengaruh stres kerja terhadap kinerja karyawan.

Stres kerja menurut Handoko (2011:200) adalah suatu kondisi ketegangan yang mempengaruhi emosi, proses berpikir dan kondisi seseorang. Stres yang terlalu besar dapat mengancam kemampuan seseorang untuk menghadapi lingkungan. Sebagai hasilnya, pada diri para karyawan berkembang berbagai macam gejala stres yang dapat mengganggu pelaksanaan kerja mereka. Dalam jangka panjang, karyawan yang tidak dapat menahan stress kerja maka karyawan tidak mampu lagi bekerja diperusahaan. Pada tahap yang semakin parah, stress bias membuat karyawan menjadi sakit atau bahkan akan mengundurkan diri (Manurung dan Ratnawati, 2012).Stress kerja merupakan suatu gejala atau perasaan yang dapat timbul dalam diri seorang pekerja dan dapat memberikan dampak dalam suatu organisasi atau perusahaan, yang akan memberikan pengaruh terhadap kepuasan karyawan dan akan mempengaruhi kinerja karyawan (Chaudhry, 2012). Stress kerja meningkat maka akan menyebabkan timbulnya keinginan keluar yang ada pada diri karyawan (Chandio et al., 2013).Stres kerja akan menimbulkan biaya yang signifikan dalam hal produktivitas yang rendah, karyawan yang sakit dan waktu yang hilang (Kouloubandi, 2012).

Stres dapat mempengaruhi kinerja karyawan. Penelitian Harianto (2008) menyatakan bahwa terdapat pengaruh negatif antara stres kerja dengan kinerja karyawan. Dar et al. (2011) menyatakan bahwa stres kerja berpengaruh negatif terhadap kinerja karyawan. Kotteswari et al. (2014) menyatakan bahwa terdapat pengaruh negatif antara stres kerja terhadap kinerja karyawan.Zafar et al. (2015) 
menyatakan bahwa terdapat hubungan positif signifikan antara stres kerja terhadap kinerja karyawan. Noviansyah dkk. (2011) menyatakan bahwa terdapat hubungan positif antara stres kerja terhadap kinerja karyawan. Berdasarkan data dan research gap yang diperoleh, maka tujuan penelitian ini yaitu : 1) untuk mengetahui dan menganalisis pengaruh langsung stress kerja terhadap kinerja karyawan pada PT. Destination Asia Bali, 2) Untuk mengetahui dan menganalisis pengaruh langsung stress kerja terhadap kepuasan kerja karyawan pada PT. Destination Asia Bali, 3) Untuk mengetahui dan menganalisis pengaruh kepuasan kerja terhadap kinerja karyawan pada PT. Destination Asia Bali, dan 4) Untuk mengetahui dan menganalisis peran Kepuasan Kerja dalam memediasi stress kerja terhadap kinerja karyawan pada PT. Destination Asia Bali.

Berdasarkan penelusuran pada kajian pustaka dan hasil-hasil penelitian sebelumnya, maka model penelitian dalam penelitian ini sebagai berikut:

\section{Gambar 1. Kerangka Konseptual Penelitian}

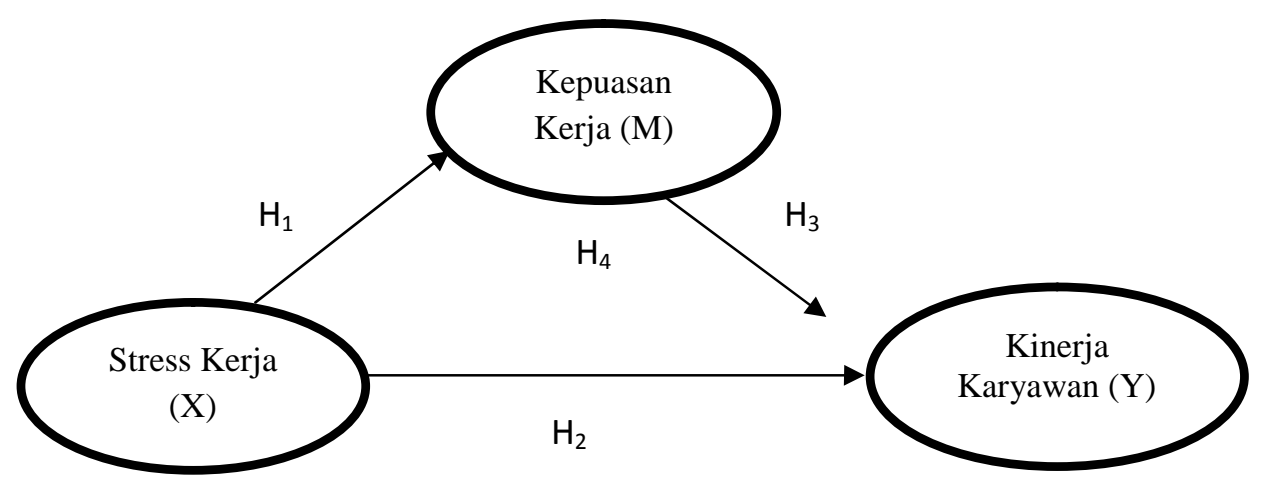

Sumber: Hasil pemikiran peneliti, 2018

Berdasarkan kerangka konsep yang ada maka hipotesis disusun, sebagai berikut. 
$\mathrm{H}_{1}$ : Stress kerja berpengaruh negatif terhadap kepuasan kerja karyawan pada PT. Destination Asia Bali.

$\mathrm{H}_{2}$ : Stress kerja berpengaruh negatif terhadap kinerja karyawan pada PT. Destination Asia Bali.

$\mathrm{H}_{3}$ : Kepuasan kerja berpengaruh positif terhadap kinerja karyawan pada PT. Destination Asia Bali.

$\mathrm{H}_{4}$ : Kepuasan kerja sebagai pemediasi antara stress kerja terhadap kinerja karyawan pada PT. Destination Asia Bali

\section{METODE PENELITIAN}

Penelitian ini digolongkan pada penelitian asosiatif (hubungan), yaitu penelitian yang bertujuan untuk mengetahui pengaruh sebab akibat dari variabel yang diteliti yaitu stress kerja, dan kepuasan kerja sebagai variabel mediasi dan kinerja karyawan. Lokasi penelitian ini di lakukan di PT. Destination Asia Bali Jalan Bypas I Gusti Ngurah Rai No. 360 Sanur Denpasar. Alasan peneliti memilih lokasi ini sebagai obyek penelitian yaitu karena adanya indikasi masalah rendahnya kepuasan kerja karyawan di PT. Destination Asia Bali yang menyebabkan kinerja karyawan menjadi menurun, kondisi tersebut diperkuat dengan data yang diperoleh peneliti mengenai banyaknya karyawan yang datang terlambat kerja dan pulang lebih awal sebelum jam kerja berakhir, serta data mengenai rendahnya tingkat kehadiran karyawan PT. Destination Asia Bali selama tahun 2017.

Populasi dalam penelitian ini adalah seluruh karyawan tetap pada PT. Destination Asia Bali. Karyawan tetap dipilih menjadi populasi penelitian karena diasumsikan bahwa karyawan tersebut memiliki informasi lebih banyak mengenai kondisi perusahaan. Jumlah karyawan tetap PT. Destination Asia Bali sebanyak 56 orang. Pengambilan sampel dalam penelitian ini menggunakan teknik sampel jenuh atau sensus, dimana seluruh populasi penelitian akan dipilih menjadi 
sampel, sehingga jumlah sampel yang digunakan dalam penelitian ini adalah sebanyak 56 orang.

Variabel yang digunakan dalam penelitian ini diuraikan dalam Tabel 4 berikut:

Tabel 4.

Identifikasi Variabel

\begin{tabular}{|c|c|c|}
\hline VARIABEL & INDIKATOR & REFERENSI \\
\hline \multirow{5}{*}{$\begin{array}{l}\text { Stres kerja } \\
\quad(\mathrm{X})\end{array}$} & 1. Beban kerja & \multirow{4}{*}{$\begin{array}{l}\text { Mangkunegara } \\
\quad(2000)\end{array}$} \\
\hline & 2. Waktu kerja & \\
\hline & 3. Umpan balik yang didapatkan & \\
\hline & 4. Tanggung jawab & \\
\hline & 1. Pekerjaan itu sendiri ( The work it self) & \multirow{4}{*}{$\begin{array}{c}\text { Cekmecelioglu et } \\
\text { al. (2012) }\end{array}$} \\
\hline \multirow{4}{*}{$\begin{array}{c}\text { Kepuasan Kerja } \\
(\mathrm{M})\end{array}$} & 2. Bayaran (Pay) & \\
\hline & 3. Kesempatan mendapatkan promosi jabatan & \\
\hline & $\begin{array}{l}\text { Promotıon opportunittes) } \\
\text { 4. Hubungan keja (Work Relation) }\end{array}$ & \\
\hline & 1. Kualitas kerja & \multirow{4}{*}{$\begin{array}{l}\text { Sedarmayanti } \\
(2009: 313)\end{array}$} \\
\hline \multirow{3}{*}{$\begin{array}{c}\text { Kinerja Karyawan } \\
\text { (Y) }\end{array}$} & 2. Kehadiran dan Ketepatan Waktu & \\
\hline & 3. Inisiatif & \\
\hline & $\begin{array}{l}\text { 4. Kemampuan } \\
\text { 5. Komunikasi }\end{array}$ & \\
\hline
\end{tabular}

Sumber : Kajian peneltian sebelumnya, 2018

Metode pengumpulan data dalam penelitian ini menggunakan wawancara, studi pustaka, dan kuisioner. Hasil penyebaran kuisioner yang sudah dijawab oleh responden kemudian di rekapitulasi dan diuji kelayakannya dengan menggunakan uji validitas dan uji reabilitas. Data yang sudah valid dan reliabel kemudian dianalisis lebih lanjut menggunakan analisis statistik deskriptif. Analisis statistik deskriptif adalah statistik yang digunakan untuk menganalisa data dengan cara mendeskripsikan atau mengambarkan data mengenai karakteristik variabel penelitian, yaitu nilai rata-rata, standar deviasi, varian, nilai minimum dan nilai maksimum (Sugiyono, 2013:207).

Teknik analisis yang digunakan dalam penelitian ini adalah teknik analisis jalur atau path analysis. Analisis jalur (path analysis) adalah perluasan dari 
Ade Agus Diama Purwa Diputra, Pengaruh Stres Kerja Terhadap Kinerja Karyawan...]

analisis regresi linier berganda. Penelitian ini terdapat tujuh hipotesis yang kemudian disusun kedalam dua model regresi. Berikut merupakan hipotesis dan model dalam penelitian ini.

Model I

Hipotesis: Stres kerja (X) berpengaruh terhadap kepuasan kerja (M)

Stuktur :M $=\boldsymbol{\beta}_{1} \boldsymbol{X}+\boldsymbol{\varepsilon}_{1}$

Model II

Hipotesis: Stres kerja (X), dan kepuasan kerja (M) berpengaruh terhadap kinerja karyawan (Y)

Struktur :Y $=\beta_{2} X+\beta_{3} M+\varepsilon_{2}$

Pengujian hipotesis mediasi dalam penelitian ini dilakukan dengan Uji Sobel (Sobel Test). Uji sobel digunakan untuk menguji kekuatan pengaruh tidak langsung variabel sters kerja (X) ke variabel kinerja karyawan (Y) melalui variabel kepuasan kerja (M). Pengaruh tidak langsung stres kerja (X) terhadap variabel kepuasan kerja (Y) melalui variabel kepuasan kerja (M) dihitung dengan mengalikan koefisien jalur X terhadap $\mathrm{M}$ (a) dengan koefisien jalur M terhadap $\mathrm{Y}$ (b) atau ab. Standard error koefisien a dan b ditulis dengan $S_{a}$ dan $S_{b}$, besarnya standard error tidak langsung (indirect effect) $\mathrm{S}_{\mathrm{ab} 1}$ dihitung dengan rumus dibawah ini:

$S a b=\sqrt{b^{2} S a^{2}+a^{2} S b^{2}+S a^{2} S b^{2}}$

Untuk menguji signifikansi pengaruh tidak langsung, maka dapat dilakukan dengan menghitung $\mathrm{t}$ dari koefisien ab dengan rumus sebagai berikut:

$$
Z=\frac{a b}{5 a b}
$$




\section{HASIL DAN PEMBAHASAN}

Responden yang digunakan sebagai sampel dalam penelitian ini berjumlah 56 orang karyawan di PT. Destination Asia Bali. Responden penelitian digambarkan dengan menyajikan karakteristiknya berdasarkan variabel demografi yaitu jenis kelamin, usia, pendidikan terakhir, dan masa kerja.

Tabel 5.

Karakteristik Responden Karyawan PT. Destination Asia Bali

\begin{tabular}{|c|c|c|c|}
\hline \multicolumn{2}{|c|}{ Klasifikasi } & $\begin{array}{c}\text { Jumlah Responden } \\
\text { (orang) }\end{array}$ & $\begin{array}{c}\text { Persentase } \\
(\%)\end{array}$ \\
\hline \multirow{2}{*}{ Jenis Kelamin } & Laki-laki & 24 & 42,86 \\
\hline & Perempuan & 32 & 57,14 \\
\hline \multicolumn{2}{|c|}{ Jumlah } & 56 & 100 \\
\hline \multirow{4}{*}{ Usia } & $20-25$ & 20 & 35,71 \\
\hline & $26-30$ & 16 & 28,57 \\
\hline & $31-35$ & 12 & 21,43 \\
\hline & $>36$ & 8 & 14,29 \\
\hline \multicolumn{2}{|c|}{ Jumlah } & 56 & 100 \\
\hline \multirow{5}{*}{$\begin{array}{c}\text { Tingkat } \\
\text { Pendidikan }\end{array}$} & SMA/SMK & 16 & 28,57 \\
\hline & D1/D2/D3 & 12 & 21,43 \\
\hline & S1 & 24 & 42,86 \\
\hline & $\mathrm{S} 2 / \mathrm{S} 3$ & 4 & 7,14 \\
\hline & Jumlah & 56 & 100 \\
\hline \multirow{5}{*}{ Masa Kerja } & $<1$ tahun & 8 & 14,29 \\
\hline & 1-2 tahun & 21 & 37,50 \\
\hline & 2-3 tahun & 17 & 30,36 \\
\hline & $>3$ tahun & 10 & 17,86 \\
\hline & Jumlah & 56 & 100 \\
\hline
\end{tabular}

Sumber : Data Primer Diolah, 2018

Tabel 5 menunjukkan bahwa karyawan di PT. Destination Asia Bali Bali di dominasi oleh responden berjenis kelamin perempuan dengan jumlah karyawan perempuan sebanyak 32 orang atau sebesar 57,14 persen dari total 56 orang karyawan. Hal tersebut mengindikasikan bahwa PT. Destination Asia Bali Bali lebih banyak mencari karyawan perempuan dibandingkan laki-laki, khususnya pada bagian leisure karena divisi tersebut lebih banyak berinteraksi dengan pelanggan. Apabila ditinjau berdasarkan faktor usia, maka dapat dilihat bahwa karyawan PT. Destination Asia Bali Bali mayoritas memiliki usia antara 20 
Ade Agus Diama Purwa Diputra, Pengaruh Stres Kerja Terhadap Kinerja Karyawan...]

sampai 25 tahun. Kelompok usia tersebut merupakan kelompok usia produktif. Faktor usia seorang karyawan dapat menunjang kegiatan organisasi dalam menghasilkan organisasi yang berkualitas. Karena dengan umur produktif yang dimiliki akan berkorelasi di dalam pencapaian tujuan organisasi tersebut.

Data responden yang diperoleh dari hasil kuesioner yang telah disebar berdasarkan tingkat pendidikan menunjukkan mayoritas karyawan di PT. Destination Asia Bali adalah kelompok responden dengan tingkat pendidikan Sarjanadengan jumlah sebanyak 24 orang atau sebesar 42,68 persen. Informasi ini memberikan gambaran bahwa karyawan di PT. Destination Asia Bali paling dominan berpendidikan terakhir Sarjana dan dianggap sudah mampu serta memadai untuk menjadi karyawan yang memiliki kompetensi untuk mencapai tujuan perusahaan.

Tabel 6.

Rekapitulasi Hasil Uji Validitas Instrumen Penelitian

\begin{tabular}{ccccc}
\hline Variabel & Indikator & Koefisien Korelasi & Sig. (2-tailed) & Cronbach's Alpha \\
\hline \multirow{2}{*}{ Stres Kerja } & $\mathrm{X}_{1}$ & 0,621 & 0,000 & \\
$(\mathrm{X})$ & $\mathrm{X}_{2}$ & 0,860 & 0,000 & 0,791 \\
& $\mathrm{X}_{3}$ & 0,805 & 0,000 & \\
& $\mathrm{X}_{4}$ & 0,623 & 0,000 & \\
Kepuasan Kerja & $\mathrm{M}_{1}$ & 0,730 & 0,000 & \\
$(\mathrm{M})$ & $\mathrm{M}_{2}$ & 0,690 & 0,000 & 0,771 \\
& $\mathrm{M}_{3}$ & 0,752 & 0,000 & \\
& $\mathrm{M}_{4}$ & 0,706 & 0,000 & \\
Kinerja Karyawan & $\mathrm{M}_{5}$ & 0,572 & 0,001 & \\
(Y) & $\mathrm{Y}_{1}$ & 0,603 & 0,000 & \\
& $\mathrm{Y}_{2}$ & 0,771 & 0,000 & \\
& $\mathrm{Y}_{3}$ & 0,764 & 0,000 & \\
& $\mathrm{Y}_{4}$ & 0,565 & 0,000 & \\
& $\mathrm{Y}_{5}$ & 0,701 & 0,000 &
\end{tabular}

Sumber : Hasil pengolahan data primer, 2018

Pengelompokkan responden berdasarkan masa kerjamenunjukkan bahwa responden yangbekerja di PT. Destination Asia Balidominan memiliki masa kerja 
selama 1 sampai 2 tahun dengan jumlah sebanyak 21 orang atau 37,50 persen. Hal ini mengindikasikan bahwa responden memiliki komitmen organisasi yang rendah dan mempunyai keinginan untuk keluar lebih besar yang disebabkan karena responden memiliki tingkat stres kerja yang tinggi.

Hasil uji instrumen penelitian pada tabel 6 menunjukkan bahwa seluruh instrumen penelitian yang digunakan untuk mengukur variabel stres kerja, kepuasan kerja dan kinerja karyawan memiliki nilai koefisien korelasi dengan skor total seluruh item pernyataan lebih besar dari 0,30 dengan signifikansi kurang dari 0,05 dan memiliki koefisien Cronbach's Alpha lebih dari 0,60. Hal ini menunjukkan bahwa butir-butir pernyataan dalam instrument penelitian tersebut valid dan reliabel. Jadi dapat dinyatakan bahwa seluruh variabel telah memenuhi syarat validitas dan reliabilitas atau kehandalan sehingga dapat digunakan untuk melakukan penelitian.

\section{Tabel 7.}

Deskripsi Jawaban Responden Terhadap Variabel Stres kerja

\begin{tabular}{|c|c|c|c|c|c|c|c|c|}
\hline \multirow{2}{*}{ No } & \multirow{2}{*}{ Pernyataan } & \multicolumn{5}{|c|}{ Frekuensi Jawaban Responden } & \multirow{2}{*}{$\begin{array}{l}\text { Rata- } \\
\text { Rata }\end{array}$} & \multirow{2}{*}{ Kriteria } \\
\hline & & STS & TS & KS & $\mathbf{S}$ & SS & & \\
\hline 1 & $\begin{array}{lr}\text { Saya merasabeban kerja } & \text { yang } \\
\text { diberikan oleh atasantidak } & \text { sesuai } \\
\text { dengan kompensasi } & \text { yang } \\
\text { diberikan } & \end{array}$ & 3 & 8 & 14 & 24 & 7 & 3,43 & Tinggi \\
\hline 2 & $\begin{array}{l}\text { Saya mampu menyelesaikan } \\
\text { pekerjaan dengan tepat waktu }\end{array}$ & 1 & 7 & 16 & 22 & 10 & 3,59 & Tinggi \\
\hline 3 & $\begin{array}{l}\text { Atasan memberikan penghargaan } \\
\text { bila saya mampu mencapai } \\
\text { prestasi kerja yang baik }\end{array}$ & 3 & 10 & 17 & 19 & 7 & 3,30 & $\begin{array}{l}\text { Cukup } \\
\text { Rendah }\end{array}$ \\
\hline 4 & $\begin{array}{l}\text { Saya bersedia menanggung semua } \\
\text { konsekuensi yang diberikan bila } \\
\text { lalai dalam menyelesaikan } \\
\text { pekerjaan }\end{array}$ & 2 & 9 & 21 & 16 & 8 & 3,34 & $\begin{array}{l}\text { Cukup } \\
\text { Rendah }\end{array}$ \\
\hline \multicolumn{7}{|c|}{ Rata-rata keseluruhan variabel Stres kerja } & 3,41 & \\
\hline
\end{tabular}

Sumber : Hasil Olahan Data, 2018 
Ade Agus Diama Purwa Diputra, Pengaruh Stres Kerja Terhadap Kinerja Karyawan...]

Secara rinci hasil penelitian mengenai jawaban responden terhadap variabel Stres kerja, kepuasan kerja dan kinerja karyawan masing-masing disajikan pada Tabel 7, Tabel 8 dan Tabel 9.

Tabel 7 menunjukkan bahwa nilai rata-rata keseluruhan variabel stres kerja sebesar 3,41. Hal ini mengindikasikan bahwa karyawan PT. Destination Asia Bali di Bali memiliki tingkat stres kerja yang tinggi. Nilai rata-rata tertinggi terdapat pada pernyataan "Saya mampu menyelesaikan pekerjaan dengan tepat waktu" dengan nilai rata-rata 3,59. Hal ini menunjukkan bahwa secara keseluruhan karyawan di PT. Destination Asia Bali sudah mampu untuk menyelesaikan pekerjaannya dengan tepat waktu. Nilai rata-rata terendah terdapat pada pernyataan "Atasan memberikan penghargaan bila saya mampu mencapai prestasi kerja yang baik", dengan nilai rata-rata sebesar 3,30. Hal ini mengindikasikan bahwa karyawan merasa kurang diberikan apresiasi dari atasan bila mereka sudah mampu mencapai prestasi kerja yang baik. Oleh karena itu, dalam upaya menurunkan tingkat stres kerja yang tinggi pada karyawan, maka sebaiknya atasan atau pimpinan PT. Destination Asia Bali di Bali selalu memberikan penghargaan kepada karyawannya secara adil bila berhasil mencapai prestasi kerja yang baik.

Tabel 8 menunjukkan bahwa nilai rata-rata keseluruhan variabel kepuasan kerja sebesar 3,17. Hal ini mengindikasikan bahwa karyawan PT. Destination Asia Bali di Bali memiliki tingkat kepuasan kerja yang cukup rendah. Nilai ratarata tertinggi hasil jawaban responden terdapat pada pernyataan "Saya senang memiliki hubungan yang baik dengan rekan kerja" dengan nilai rata-rata 3,50. Hal ini menunjukkan bahwa secara keseluruhan karyawan di PT. Destination Asia 
Balisenang memiliki hubungan yang baik dengan rekan kerja, karena karyawan PT. Destination Asia Balimemiliki sikap saling tolong menolong dengan sesama rekan kerjanya, sehingga terjalin hubungan yang baik. Nilai rata-rata terendah terdapat pada pernyataan "Saya puas dengan kesempatan promosi yang ada", dengan nilai rata-rata sebesar 2,91.

Tabel 8.

Deskripsi Jawaban Responden Terhadap Variabel Kepuasan kerja

\begin{tabular}{|c|c|c|c|c|c|c|c|c|}
\hline \multirow{2}{*}{ No } & \multirow{2}{*}{ Pernyataan } & \multicolumn{5}{|c|}{ Frekuensi Jawaban Responden } & \multirow{2}{*}{ Rata-Rata } & \multirow{2}{*}{ Kriteria } \\
\hline & & STS & TS & $\mathbf{K S}$ & $\mathbf{S}$ & SS & & \\
\hline 1 & $\begin{array}{l}\text { Saya puas dengan pekerjaan } \\
\text { saya }\end{array}$ & 6 & 13 & 14 & 20 & 3 & 3,02 & $\begin{array}{l}\text { Cukup } \\
\text { Rendah }\end{array}$ \\
\hline 2 & $\begin{array}{l}\text { Balas jasa yang diterima } \\
\text { sesuai dengan harapan }\end{array}$ & 5 & 9 & 18 & 20 & 4 & 3,16 & $\begin{array}{l}\text { Cukup } \\
\text { Rendah }\end{array}$ \\
\hline 3 & $\begin{array}{l}\text { Saya puas dengan } \\
\text { kesempatan promosi yang } \\
\text { ada }\end{array}$ & 7 & 12 & 19 & 15 & 3 & 2,91 & $\begin{array}{l}\text { Cukup } \\
\text { Rendah }\end{array}$ \\
\hline 4 & $\begin{array}{l}\text { Saya puas dengan supervisi } \\
\text { yang ada }\end{array}$ & 6 & 7 & 18 & 16 & 9 & 3,27 & $\begin{array}{l}\text { Cukup } \\
\text { Rendah }\end{array}$ \\
\hline 5 & $\begin{array}{l}\text { Saya senang memiliki } \\
\text { hubungan yang baik dengan } \\
\text { rekan kerja }\end{array}$ & 1 & 8 & 18 & 20 & 9 & 3,50 & Tinggi \\
\hline & Rata-rata keseluruhan & riabel & epua & n ke & & & 3,17 & $\begin{array}{l}\text { Cukup } \\
\text { Rendah }\end{array}$ \\
\hline
\end{tabular}

Sumber : Hasil Olahan Data, 2018

Hal ini mengindikasikan bahwa karyawan merasa kurang mendapatkan kesempatan promosi yang ada di PT. Destination Asia Bali. Oleh karena itu, dalam upaya meningkatkan kepuasan kerja, maka sebaiknya atasan atau pimpinan PT. Destination Asia Bali di Bali memberi kesempatan promosi secara adil bagi seluruh karyawan yang telah berhasil mencapai prestasi kerja yang baik.

Tabel 9 menunjukkan bahwa nilai rata-rata keseluruhan variabel kinerja karyawan sebesar 3,26. Hal ini mengindikasikan bahwa kinerja karyawan PT. Destination Asia Bali di Bali tergolong cukup rendah. Nilai rata-rata tertinggi 
Ade Agus Diama Purwa Diputra, Pengaruh Stres Kerja Terhadap Kinerja Karyawan...]

hasil jawaban responden terdapat pada pernyataan "Saya selalu berusaha untuk menyelesaikan tugas dengan penuh rasa tanggung jawab untuk mencapai hasil yang maksimal" dengan nilai rata-rata 3,54.

\section{Tabel 9.}

Deskripsi Jawaban Responden Terhadap Variabel Kinerja karyawan

\begin{tabular}{|c|c|c|c|c|c|c|c|c|}
\hline \multirow{2}{*}{ No } & \multirow{2}{*}{ Pernyataan } & \multicolumn{5}{|c|}{ Frekuensi Jawaban Responden } & \multirow{2}{*}{$\begin{array}{l}\text { Rata- } \\
\text { Rata }\end{array}$} & \multirow{2}{*}{ Kriteria } \\
\hline & & STS & TS & KS & $\mathbf{S}$ & SS & & \\
\hline 1 & $\begin{array}{l}\text { Saya selalu berusaha untuk } \\
\text { menyelesaikan tugas dengan } \\
\text { penuh rasa tanggung jawab } \\
\text { untuk mencapai hasil yang } \\
\text { maksimal }\end{array}$ & 1 & 9 & 15 & 21 & 10 & 3,54 & Tinggi \\
\hline 2 & $\begin{array}{l}\text { Saya selalu } \begin{array}{l}\text { berusaha } \\
\text { menyelesaikan } \\
\text { tugas-tugas }\end{array} \\
\text { yang diberikan sesuai dengan } \\
\text { target yang telah ditentukan }\end{array}$ & 4 & 10 & 14 & 11 & 17 & 3,48 & Tinggi \\
\hline 3 & $\begin{array}{l}\text { Saya dapat mengerjakan } \\
\text { pekerjaan dengan efektif serta } \\
\text { efisiensi sehingga tidak perlu } \\
\text { banyak intruksi dari atasan }\end{array}$ & 3 & 14 & 17 & 13 & 9 & 3,20 & $\begin{array}{l}\text { Cukup } \\
\text { Rendah }\end{array}$ \\
\hline 4 & $\begin{array}{l}\text { Saya mendapatkan pelatihan } \\
\text { serta pendidikan yang } \\
\text { dilaksanakan oleh perusahaan }\end{array}$ & 8 & 12 & 18 & 11 & 7 & 2,95 & $\begin{array}{l}\text { Cukup } \\
\text { Rendah }\end{array}$ \\
\hline 5 & $\begin{array}{l}\text { Komunikasi saya dengan } \\
\text { pimpinan berjalan dengan baik }\end{array}$ & 4 & 14 & 15 & 14 & 9 & 3,18 & $\begin{array}{l}\text { Cukup } \\
\text { Rendah }\end{array}$ \\
\hline & Rata-rata keseluruhan va & gel & & r & & & 3,26 & \\
\hline
\end{tabular}

Sumber : Hasil Olahan Data, 2018

Hal ini menunjukkan bahwa secara keseluruhan karyawan di PT. Destination Asia Baliselalu berusaha untuk menyelesaikan tugas dengan penuh rasa tanggung jawab untuk mencapai hasil yang maksimal. Nilai rata-rata terendah terdapat pada pernyataan "Saya mendapatkan pelatihan serta pendidikan yang dilaksanakan oleh perusahaan", dengan nilai rata-rata sebesar 2,95. Hal ini mengindikasikan bahwa karyawan merasa belum mendapatkan pelatihan serta pendidikan yang dilaksanakan oleh perusahaan". Oleh karena itu, dalam upaya meningkatkan kinerja karyawan, maka sebaiknya atasan atau pimpinan PT. 
Destination Asia Bali di Bali memberi pelatihan serta pendidikan secara adil bagi seluruh karyawan setiap bulannya agar kinerja karyawan dapat meningkatkan.

Pengujian data dalam penelitian ini menggunakan teknik analisis jalur (Path Analysis), dimana analisis jalur adalah perluasan dari analisis regresi linear berganda untuk menguji hubungan kausalitas antara 2 atau lebih variabel. Perhitungan koefisien path dilakukan dengan analisis regresi melalui software SPSS 22.0 for Windows, diperoleh hasil yang ditunjukan pada Tabel 10.

Tabel 10.

Hasil Analisis Jalur 1

\begin{tabular}{lcccc}
\hline \multicolumn{1}{c}{ Variabel } & Standardized Coefficients & Std. Error & t hitung & Sig. uji t \\
\hline (Constant) & 26,468 & 2,097 & 12,619 & 0,000 \\
Stres kerja (X) & $-0,579$ & 0,149 & $-5,222$ & 0,000 \\
R Square & 0,336 & & & \\
F Statistik & 27,269 & & & \\
Sig. Uji F & 0,000 & & & \\
Sumber: Data primer diolah, 2018 & & &
\end{tabular}

Berdasarkan hasil analisis jalur substruktur 1 seperti yang disajikan pada Tabel 10, maka dapat dibuat persamaan struktural sebagai berikut :

$$
M=26,468-0,579 X+e_{1}
$$

Besarnya pengaruh variabel bebas terhadap variabel terikat yang ditunjukkan oleh nilai determinasi total (R Square) sebesar 0,336 mempunyai arti bahwa sebesar 33,6\% variasi kepuasan kerjadipengaruhi oleh variasi stres kerja, sedangkan sisanya sebesar $66,4 \%$ dijelaskan oleh faktor lain yang tidak dimasukkan ke dalam model.

Berdasarkan hasil analisis jalur substruktur 2 seperti yang disajikan pada Tabel 11, maka dapat dibuat persamaan struktural sebagai berikut :

$$
\mathrm{Y}=13,805-0,283 \mathrm{X}+0,479 \mathrm{M}+\mathrm{e}_{2}
$$


Tabel 11.

Hasil Analisis Jalur 2

\begin{tabular}{lcccc}
\hline \multicolumn{1}{c}{ Variabel } & Standardized Coefficients & Std. Error & t hitung & Sig. uji t \\
\hline (Constant) & 13.805 & 3.950 & 3.495 & .001 \\
Stres kerja (X) & -.283 & .173 & -2.295 & .026 \\
Kepuasan kerja (M) & .479 & .129 & 3.891 & .000 \\
\hline R Square & 0,466 & & & \\
F Statistik & 23,144 & & \\
Signifikansi Uji F & 0,000 & & & \\
\hline Sumber $:$ Data primer diolah, 2018 & & & &
\end{tabular}

Besarnya pengaruh variabel bebas terhadap variabel terikat yang ditunjukkan oleh nilai determinasi total (R Square) sebesar 0,466 mempunyai arti bahwa sebesar $46,6 \%$ variasi Kinerja karyawan dipengaruhi oleh variasi stres kerja dan kepuasan kerja, sedangkan sisanya sebesar 53,4\% dijelaskan oleh faktor lain yang tidak dimasukkan ke dalam model.

Berdasarkan model substruktur 1 dan substruktur 2, maka dapat disusun model diagram jalur akhir. Sebelum menyusun model diagram jalur akhir, terlebih dahulu dihitung nilai standar eror sebagai berikut :

$$
\begin{aligned}
& \mathrm{Pe}_{\mathrm{i}}=\sqrt{1-\mathrm{R}_{\mathrm{i}}^{2}} \\
& \mathrm{Pe}_{1}=\sqrt{1-R_{1}^{2}}=\sqrt{1-0,336}=0,815 \\
& \mathrm{Pe}_{2}=\sqrt{1-R_{2}{ }^{2}}=\sqrt{1-0,466}=0,731
\end{aligned}
$$

Berdasarkan perhitungan pengaruh error (Pei), didapatkan hasil pengaruh error $\left(\mathrm{Pe}_{1}\right)$ sebesar 0,815 dan pengaruh error $\left(\mathrm{Pe}_{2}\right)$ sebesar 0,731 . Hasil koefisien determinasi total adalah sebagai berikut :

$$
\begin{aligned}
\mathrm{R}_{\mathrm{m}}^{2} & =1-\left(\mathrm{Pe}_{1}\right)^{2}\left(\mathrm{Pe}_{2}\right)^{2} \\
& =1-(0,815)^{2}(0,731)^{2}=0,646
\end{aligned}
$$


Nilai determinasi total sebesar 0,646 mempunyai arti bahwa sebesar 64,6\% variasi Kinerja karyawan dipengaruhi oleh variasi stres kerjadan kepuasan kerja, sedangkan sisanya sebesar $35,4 \%$ djelaskan oleh faktor lain yang tidak dimasukkan ke dalam model.

Hasil analisis jalur pada Tabel 10 menunjukkan pengaruh stres kerja terhadap kepuasan kerja memperoleh nilai signifikansi sebesar 0,000 dengan nilai koefisien beta $-0,579$. Nilai Signifikansi $0,000<0,05$ mengindikasikan bahwa $\mathrm{H}_{0}$ ditolak dan $\mathrm{H}_{1}$ diterima. Hasil ini mempunyai arti bahwa Stres kerja berpengaruh negatif dan signifikan terhadap Kepuasan kerjakaryawan PT. Destination Asia Bali di Bali.

Hasil analisis pengaruh Stres kerja terhadap Kinerja karyawan diperoleh nilai Signifikansi sebesar 0,026 dengan nilai koefisien beta $-0,283$. Nilai Signifikansi $0,026<0,05$ mengindikasikan bahwa $\mathrm{H}_{0}$ ditolak dan $\mathrm{H}_{2}$ diterima. Hasil ini mempunyai arti bahwa Stres kerjaberpengaruh negatif dan signifikan terhadap Kinerja karyawan pada PT. Destination Asia Bali di Bali.

Hasil analisis pengaruh Kepuasan kerja terhadap Kinerja karyawan diperoleh nilai Signifikansi sebesar 0,000 dengan nilai koefisien beta 0,479. Nilai Signifikansi $0,000<0,05$ mengindikasikan bahwa $\mathrm{H}_{0}$ ditolak dan $\mathrm{H}_{3}$ diterima. Hasil ini mempunyai arti bahwa Kepuasan kerjaberpengaruh positif dan signifikan terhadap Kinerja karyawan pada PT. Destination Asia Bali di Bali.

Perhitungan pengaruh antar variabel tersebut dirangkum dalam Tabel 12. Tabel 12 menunjukkan bahwa lebih besar total pengaruh stres kerja terhadap 
Ade Agus Diama Purwa Diputra, Pengaruh Stres Kerja Terhadap Kinerja Karyawan...]

kinerja karyawan yang melalui kepuasan kerja, daripada pengaruh langsung stres kerja terhadap kinerja karyawan tanpa melalui variabel kepuasan kerja.

Tabel 12.

Pengaruh Langsung dan Tidak Langsung serta Pengaruh Total Stres kerja (X), Kepuasan kerja (M), dan Kinerja karyawan (Y)

\begin{tabular}{cccc}
\hline $\begin{array}{c}\text { Pengaruh } \\
\text { Variabel }\end{array}$ & $\begin{array}{c}\text { Pengaruh } \\
\text { Langsung }\end{array}$ & $\begin{array}{c}\text { Pengaruh Tidak Langsung Melalui } \\
\text { Kepuasan kerja } \\
(\mathbf{M})(\boldsymbol{\beta 1} \mathbf{x} \boldsymbol{\beta 3})\end{array}$ & Pengaruh Total \\
\hline $\mathrm{X} \rightarrow \mathrm{M}$ & $-0,579$ & - & $-0,579$ \\
$\mathrm{X} \rightarrow \mathrm{Y}$ & $-0,397$ & 0,291 & $-0,688$ \\
$\mathrm{M} \rightarrow \mathrm{Y}$ & 0,479 & - & 0,479 \\
\hline
\end{tabular}

Sumber :Data primer diolah, 2017

Pengujian pengaruh tidak langsung variabel stres kerja (X) terhadap variabel kinerja karyawan (Y) melalui variabel kepuasan kerja (M), dihitung menggunakan uji sobel. Hasil uji sobel memperoleh nilai Z hitung sebesar 2,6393> 1,96. Artinya Kepuasan kerja (M) merupakan variabel yang memediasi stres kerja (X) terhadap kinerja karyawan (Y) pada PT. Destination Asia Bali atau dengan kata lain stres kerja berpengaruh secara tidak langsung terhadap kinerja karyawanmelalui kepuasan kerja.

\section{Pengaruh Stres kerja Terhadap Kepuasan kerja}

Hasil analisis menunjukkan bahwa stres kerja berpengaruh negatif dan signifikan terhadap kepuasan kerja. Hal ini memiliki makna bahwa semakin tinggi tingkat stres kerja yang dimiliki Karyawan PT. Destination Asia Bali, maka semakin rendah kepuasan kerja yang akan terbentuk dalam diri karyawan tersebut. Begitu pula sebaliknya, semakin rendah tingkat stres kerja yang dimiliki Karyawan PT. Destination Asia Bali, maka semakin tinggi kepuasan kerja yang akan terbentuk dalam diri karyawan tersebut. dari hasil penelitian para ahli maka 
dapat disimpulkan Kepuasan kerja yang tinggi mengaplikasikan bahwa karyawan senang dan nyaman kepada lingkungan kerja organisasi serta mendapatkan jerih payah yang yang sesuai dari hasil kerjanya (Aziri, 2011). Fakta lain menyebutkan bahwa seorang dengan tingkat kepuasan kerja yang tinggi memiliki sikap positif terhadap pekerjaan, sementara orang yang tidak puas akibat stres dengan pekerjaan memiliki sikap negatif terhadap pekerjaan yang dihadapinya (Taskina, 2009).

Hasil tersebut mengindikasikan bahwa nilai - nilai yang terkandung dalam stres kerja mampu berdampak nyata terhadap kepuasan kerjakaryawan PT. Destination Asia Bali. Stres kerjayang diukur berdasarkan indikator: beban kerja, waktu kerja, umpan balik yang didapatkandan tanggung jawab terbukti mampu mempengaruhikepuasan karyawan terhadap pekerjaan itu sendiri (the work it self), bayaran (pay), kesempatan mendapatkan promosi jabatan (promotion opportunities) dan hubungan kerja (work relation) karyawan PT. Destination Asia Bali. Temuan ini dapat diartikan bahwa apabila faktor-faktor pembentukstres kerjapada karyawanPT. Destination Asia Bali dikurangi, maka akan mampu memberikan kontribusi yang signifikan untuk meningkatkan kepuasan kerja karyawan.

Penelitian ini mendukung beberapa hasil penelitian sebelumnya dan konsisten dengan hasil penelitian Faqihudin dan Gunistiyo (2010) yang menemukan hasil bahwa stress kerja mempunyai pengaruh signifikan dan negative terhadap kepuasan kerja karyawan. Penelitian tersebut menjelaskan bahwa stres kerja yang dimiliki karyawan dapat berpengaruh secara langsung 
Ade Agus Diama Purwa Diputra, Pengaruh Stres Kerja Terhadap Kinerja Karyawan...]

dalam membentuk kepuasan kerja. Penelitian serupa yang dilakukan Jahanzeb (2010), Mansoor et al. (2011), dan Iqbal (2012) juga memperoleh hasil bahwa stres kerja mempunyai pengaruh yang negatif terhadap kepuasan kerja.

\section{Pengaruh Stres kerja Terhadap Kinerja karyawan}

Hasil analisis menunjukkan bahwa stres kerja berpengaruh negatif dan signifikan terhadap kinerja karyawan. Hal ini memiliki makna bahwa semakin tinggi tingkat stres kerja yang dimiliki Karyawan PT. Destination Asia Bali, maka semakin rendah kinerja karyawan yang akan terbentuk. Begitu pula sebaliknya, semakin rendah tingkat stres kerja yang di miliki Karyawan PT. Destination Asia Bali, maka semakin tinggi kinerja karyawan yang akan terbentuk. Dari hasil penelitian oleh para ahli maka dapat disimpukan stres kerja adalah kondisi ketegangan yang mempengaruhi emosi, proses berpikir dan kondisi seseorang. Stres yang terlalu besar dapat mengancam kemampuan seseorang untuk menghadapi lingkungan. Sebagai hasilnya, pada diri para karyawan berkembang berbagai macam gejala stres yang dapat mengganggu pelaksanaan kerja mereka (Handoko, 2011:200).

Hasil tersebut mengindikasikan bahwa nilai - nilai yang terkandung dalam stres kerja mampu berdampak nyata terhadap kinerja karyawan PT. Destination Asia Bali. Stres kerja yang diukur berdasarkan indikator: beban kerja, waktu kerja, umpan balik yang didapatkandan tanggung jawab terbukti mampu mempengaruhi kualitas kerja yang dicapai, Kehadiran dan Ketepatan Waktu, Inisiatif, Kemampuan dan Komunikasi karyawan PT. Destination Asia Bali. Temuan ini dapat diartikan bahwa apabila faktor-faktor pembentuk stres kerja 
pada karyawan PT. Destination Asia Bali dapat dikurangi, maka akan mampu memberikan kontribusi yang signifikan untuk meningkatkan kinerja karyawan.

Penelitian ini mendukung beberapa hasil penelitian sebelumnya dan konsisten dengan hasil penelitian Adetayo et al. (2014) yang menemukan hasil bahwa stres kerja berpengaruh negatif signifikan terhadap kinerja karyawan, karena beban kerja yang berlebihan, pengembangan karier, masalah keluarga dan masalah organisasi dapat menurunkan kinerja karyawan tersebut dimana karyawan merasa capek, gelisah, tidak bahagia, sakit kepala, lemah serta mudah marah. Penelitian serupa yang dilakukan Zeb et al. (2015), Usman et al. (2014), Arbabisarjou et al. (2013), Bashir et al. (2010), dan Rizwan (2014) juga memperoleh hasil bahwa terdapat hubungan yang negatif antara stres kerja dengan kinerja, hal ini berarti karyawan yang tingkat stres nya rendah akan memiliki kinerja yang lebih tinggi dibandingkan dengan karyawan yang memiliki tingkat stres yang lebih tinggi.

\section{Pengaruh Kepuasan kerja Terhadap Kinerja karyawan}

Hasil analisis menunjukkan bahwa kepuasan kerja berpengaruh positif dan signifikan terhadap kinerja karyawan. Hal ini memiliki makna bahwa semakin tinggi kepuasan kerja yang dirasakan Karyawan PT. Destination Asia Bali, maka semakin tinggi pula kinerja karyawan yang akan terbentuk pada karyawan tersebut. Begitu pula sebaliknya, semakin rendah kepuasan kerja yang dirasakan karyawan PT. Destination Asia Bali, maka semakin rendah pula kinerja karyawan yang akan terbentuk pada karyawan tersebut. Dari penelitian oleh para ahli dapat disimpulkan kinerja merupakan perilaku nyata yang ditampilkan setiap orang 
Ade Agus Diama Purwa Diputra, Pengaruh Stres Kerja Terhadap Kinerja Karyawan...]

sebagai prestasi kerja yang dihasilkan oleh karyawan sesuai dengan perannya dalam perusahaan. Kinerja karyawan merupakan suatu hal yang sangat penting dalam upaya perusahaan untuk mencapai tujuannya (Rivai, 2008:131).

Hasil tersebut mengindikasikan bahwa nilai - nilai yang terkandung dalam kepuasan kerja mampu dipersepsikan dengan baik dan berdampak nyata terhadap kinerja karyawan PT. Destination Asia Bali. Kepuasan kerja yang diukur berdasarkan indikator: pekerjaan itu sendiri (the work it self), bayaran (pay), kesempatan mendapatkan promosi jabatan (promotion opportunities) dan hubungan kerja (work relation) terbukti mampu meningkatkan kualitas kerja yang dicapai, kehadiran dan ketepatan waktu, inisiatif, kemampuan dan komunikasi karyawan PT. Destination Asia Bali. Temuan ini dapat diartikan bahwa apabila kepuasan kerja karyawan dapat ditingkatkan, maka akan mampu memberikan kontribusi yang signifikan terhadap kinerja karyawan.

Penelitian ini mendukung beberapa hasil penelitian sebelumnya dan konsisten dengan hasil penelitian Smayling dan Miller (2012) yang mengungkapkan bahwa kepuasan kerja secara signifikan memiliki hubungan dengan kinerja karyawan, namun fakta yang ditemukan bahwa hubungan ini terjadi antara atasan dan bawahan dengan jenis kelamin/ gender yang sama. Hasil penelitian menjelaskan bahwa semakin tinggi rasa kepuasan kerja karyawan maka akan mampu meningkatkan kinerja karyawan menjadi lebih baik. Penelitian serupa yang dilakukan Tobing (2009), Chandra (2013), Suyuti dkk. (2009), Wijayanti dan Subudi (2014) serta Rozi (2006) juga memperoleh hasil bahwa kepuasan kerja berpengaruh positif dan signifikan terhadap kinerja karyawan. Hal 
tersebut berarti bahwa rasa kepuasan kerja yang dimiliki pekerja membuat pekerja untuk meningkatkan kinerjanya.

\section{Peran Kepuasan kerja memediasi pengaruh stres kerja pada kinerja karyawan}

Berdasarkan hasil uji Sobel, ditemukan pengaruh yang positif antara variabel stres kerja terhadap kinerja karyawan melalui variabel kepuasan kerja. Hasil penelitian ini didukung oleh penelitian yang dilakukanoleh Adawiyah (2015) menemukan bahwa kepuasan kerja berpengaruh positif dan signifikan dalam memediasi stres kerja terhadap kinerja karyawan PT. Destintion Asia. Dengan demikian, karyawan yang mampu menekan tingkat stres kerjanya akan terdorong untuk membentuk kepuasan kerja karyawan dan dengan memiliki rasa kepuasan kerja tersebut maka akan mampu meningkatkan kinerja karyawan dalam menyelesaikan pekerjaannya. kepuasan kerja secara positif dan signifikan memediasi pengaruh stres kerja terhadap kinerja karyawan PT. Destination Asia Bali, memiliki makna bahwameskipun adanya stres kerja tetapi apabila ditunjang dengan kepuasan kerja yang tinggi maka karyawan akan memiliki kinerja yang maksimal dalam bekerja.

\section{SIMPULAN DAN SARAN}

Simpulan yang dapat diberikan berdasarkan pada pembahasan dan hasil analisis dalam penelitian ini yaitu yang pertama, Stres kerja berpengaruh negatif dan signfikan terhadap kepuasan kerja karyawan PT. Destination Asia Bali. Hal ini memiliki makna bahwa semakin tinggi tingkat stres kerja yang dimiliki Karyawan PT. Destination Asia Bali, maka semakin rendah kepuasan kerja yang akan terbentuk dalam diri karyawan tersebut. Begitu pula sebaliknya, semakin 
Ade Agus Diama Purwa Diputra, Pengaruh Stres Kerja Terhadap Kinerja Karyawan...]

rendah tingkat stres kerja yang di miliki Karyawan PT. Destination Asia Bali, maka semakin tinggi kepuasan kerja yang akan terbentuk dalam diri karyawan tersebut. Kedua, Stres kerja berpengaruh negatif dan signfikan terhadap kinerja karyawan PT. Destination Asia Bali. Hal ini memiliki makna bahwa semakin tinggi tingkat stres kerja yang dimiliki Karyawan PT. Destination Asia Bali, maka semakin rendah kinerja karyawan yang akan terbentuk. Begitu pula sebaliknya, semakin rendah tingkat stres kerja yang di miliki Karyawan PT. Destination Asia Bali, maka semakin tinggi kinerja karyawan yang akan terbentuk. Ketiga, Kepuasan kerja berpengaruh positif dan signifikan terhadap Kinerja karyawan PT. Destination Asia Bali. Hal ini memiliki makna bahwa semakin tinggi kepuasan kerja yang dirasakan Karyawan PT. Destination Asia Bali, maka semakin tinggi pula kinerja karyawan yang akan terbentuk pada karyawan tersebut. Begitu pula sebaliknya, semakin rendah kepuasan kerja yang dirasakan karyawan PT. Destination Asia Bali, maka semakin rendah pula kinerja karyawan yang akan terbentuk pada karyawan tersebut. Keempat, Kepuasan kerja secara positif dan signifikan memediasi pengaruh stres kerja terhadap kinerja karyawan PT. Destination Asia Bali. Hal ini menunjukan bahwa meskipun adanya stres kerja tetapi apabila ditunjang dengan kepuasan kerja yang tinggi maka karyawan akan memiliki kinerja yang maksimal dalam bekerja.

Saran yang dapat diberikan berdasarkan hasil penelitian ini yaitu Dalam upaya menurunkan tingkat stres kerja yang tinggi pada karyawan, maka sebaiknya atasan atau pimpinan PT. Destination Asia Bali di Bali selalu memberikan penghargaan kepada karyawannya secara adil bila berhasil mencapai prestasi kerja 
yang baik. Kemudian, dalam upaya meningkatkan kepuasan kerja, maka sebaiknya atasan atau pimpinan PT. Destination Asia Bali di Bali memberi kesempatan promosi secara adil bagi seluruh karyawan yang telah berhasil mencapai prestasi kerja yang baik. Selanjutnya, dalam upaya meningkatkan kinerja karyawan, maka sebaiknya atasan atau pimpinan PT. Destination Asia Bali di Bali memberi pelatihan serta pendidikan secara adil bagi seluruh karyawan setiap bulannya agar kinerja karyawan dapat meningkatkan.

\section{REFERENSI}

Adawiyah Robiatul, Siswanto. (2015). Stres Kerja Pengaruhnya Terhadap Kinerja Karyawan dengan Kepuasan Kerja Sebagai Variabel Mediasi. Jurnal ElDinar, 3(1), pp: 27-40.

Adetayo Joshua Olusegun, Ajani Jhon Oluwasayo \& Olabisi Olawoyim. (2014). An Overview of the Effect of Job Stress on employees Performance in Nigeria Tertiary Hospitals. Scientific Review Article, 60(4), pp: 139-153.

Arbabisarjou Azisollah, Ajdari Zaman, Omeidi Khaled \& Jalalinejad Razieh. (2013). The Relationship between Job Stress an Performance Among The Hospitals Nurse. World of Science Journal, 13(2), pp: 181-188.

Aziri, B. (2011). Job satisfaction: A literature review. Management Research and Practice, 3(4). pp:77-86.

Bashir, Usman, and Muhammad Ismail Ramay. (2010). Impact of Stress Employees Job Performance A Study on Banking Secret of Pakistan. Internasional Journal of Marketing Studies, 2(1): pp: 122-126.

Cahya, Putriana. (2018). Destination Travellers Choice 2018 https://www.idntimes.com/travel/destination/putriana-cahya/bali

Cekmecelioglu, Hulya Gundus, Ayse Gunsel dan Ulutas, Tugce. (2012). Effect of Emotional Intelegence on Job Satisfaction: An Empiral Study on Call Center Employees. Procedia-Social and Behavior Science. 58. pp: 363-369.

Chandio, Javed Ahmed, Ashique Ali Jhatial dan Rafia Mallah. (2013). Modeling The Relationship Of Uncelar Career Developmen With Jib Dissatisfaction, Job Sress and Employees Turnover Intention: Sructural Equation Modeling Approach. Journal of Arts Humamanities. 41 (41). Pp:55-57. 
Chen, Ying-Chang., Wen Cheng Wang and Ying Chien Chu. (2010). Structural Investigation of the Relationship between Working Satisfaction and Employees Turnover. Journal Human Resource and Adult Learning. 6(1).

Dar, Laiba., Anum Akmal, Muhammad Akram Naseem, and Kashif Ud Din Khan. (2011). Impact of Stress on Employees Job Performance in Business Sector of Pakistan. Global Journal of Management and Business, 11(6): pp: $1-4$.

Faqihudin, M. dan Gunistiyo. (2010). Pengaruh Stres Kerja Terhadap Kepuasan Kerja dan Intensi Meninggalkan Organisasi Pada Bank-Bank Milik Negara di Kota Tegal. Jurnal Sekolah Bisnis dan Manajemen Institut Teknologi Bandung.

Firmansah, Moh.Irsan., dan Raeny Dwi Santy. (2011). Pengaruh Iklim Organisasi dan Karakteristik Pekerjaan Terhadap Kepuasan Kerja Karyawan di Lingkungan Pemerintah Daerah Kabupaten Sukabumi. Majalah Ilmiah Unikom, 6(2), h: 225-232.

Harianto, Feri., Putu Artama Wiguna dan Dedy Rakhmad. (2008). Pengaruh Stres Kerja, dan Gaya Kepemimpinan terhadap Kinerja Tenaga Kerja Pada Proyek Mall Yani Golf di Surabaya. Jurnal Iptek, 11(3):h: 139-145.

Iqbal Muhammad. (2012). Impact of Job Stress on Job Satisfaction Among Air Traffict Controller of Civil Auiantion Authority An Empirical Study From Pakistan. International Journal of Human Reseorce Studies, 2(2), pp: 53-70.

Jahanzeb, Humaria. (2010). The Impact of Job Stress on Job Satisfaction Among Academic Faculty of a Mega Distance Learning Institution In Pakistan. Mustang Journal of Business \& Ethics, 8(4): pp: 31-50

Kouloubandi, Abdollah. (2012). Analysis The Relationship Between Job Stress, Intrisic Motivation and Employes Creativity in Islamic Republic of Iran Railways Organization. Interdiscipplinary Journal of Contemporary Researah in Business. 4(8), pp: 39-53

Mansoor, Muhammad., Mohammad Ali Jinnah., Sabtain Fida., Saima Nasir and Zubair Ahmad. (2011). The Impact of Job Stress on Employees Job Satisfaction a Study on Telecommunication Sector of Pakistan. Journal of Business Studies Quarterly, 2(3), pp: 50-56.

Noviansyah dan Zunaidah. (2011). Pengaruh Stres Kerja dan Motivasi Kerja Terhadap Kinerja Karyawan PT. Perkebunan Minanga Ogan Baturaja. Jurnal Manajemen dan Bisnis Brawijaya, 9(18) : h: 44-58. 
Rizwan Muhammad. (2014). Antecedents of Job Stress and its Impact on Job Performance and Job Satisfaction. International Journal of Learning \& Development, 4(2), pp:187-203.

Smayling, Miles dan Miller, Howard.(2012). Job Satisfaction an Job Performance at the Intership Level. Journal of Leadership, Accountability and Ethics, 9(11), pp : 27-33.

Susanty, Etty. (2012). Pengaruh Iklim Organisasi Terhadap Kepuasan Kerja dan Komitmen Karyawan Pada Universitas Terbuka. Jurnal Organisasi dan Manajemen. 8(2), h:121-134.

Usman Ali, Warraich., Ahmed Riszwan Raheem, Ahmad Nawaz and Khoso Imamuddin. (2014). Impact of Stress on Job Performance : An Empirical study of the Employees of Private Sector Universities of Karachi, Pakistan. Research Journal of Management Sciences, 3(7). pp: 14-17.

Wijayanti, Ni Ketut Ayu Lestari dan Subudi, Made. (2014). Pengaruh Kepemimpinan, Kompensasi Finansial terhadap Kepuasan Kerja Serta Dampaknya terhadap Kinerja Karyawan. e-Jurnal Manajemen Universitas Udayana, 3(11), h:3396-3414.

Zafar, Qadoos, Ayesha Ali, Tayyab Hameed, Toqqer Ilyas and Hafiz Imran Younas. (2015). Influence of Job Stress on Employees Performance in Pakistan. American Journal of Social Science Research, 1(4) : pp: 221-225.

Zeb Alam, Gouhar Saeed and Shafiqur Rehman. (2015). The Impact of Job Stress on Employee's Performance: Investigating The Moderating Effect of Employees Motivation. City University Research Journal, 5(1): pp: 120-129 